\title{
DESIGNING AN INTELLIGENT MANUFACTURING SYSTEM BASED ON THE CONCEPT OF MES
}

\author{
KOKLA, M.
}

Abstract: A different manufacturing concept (Lean, Six Sigma) has been used extensively to improve the results of manufacturing enterprises. Today there is an abundance of literature on many techniques and methods, yet there is very little information on integrating techniques with a Manufacturing Execution System (MES) and its impact on various industries. This article describes the results of a stage in a case study aimed at establishing an expert system for developing integrated Manufacturing Execution Systems. The model concept can be used to develop the fields of Intelligent Production Planning, Monitoring and Diagnosis, which are part of Intelligent Manufacturing Technology (IMT).

Key words: manufacturing, intelligent manufacturing system, lean
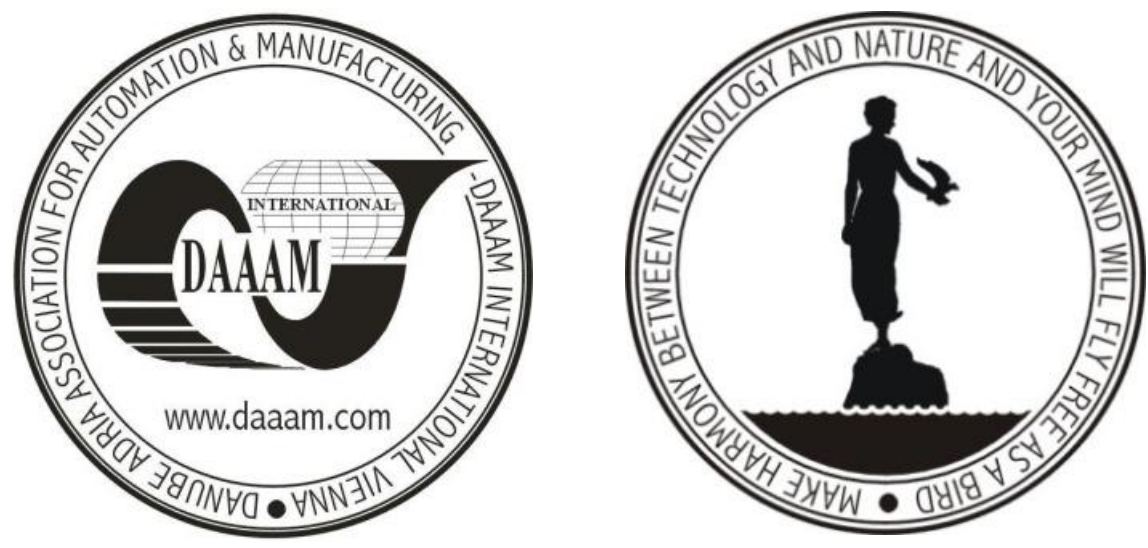

Authors' data: Ph.D. candidate Kokla, M[arko], Tallinn University of Technology, Ehitajate tee 5, 19086, Tallinn, Estonia, marko.kokla@mail.ee

Publication citation: Kokla, M[arko] (2012). Designing an Intelligent Manufacturing System Based on the Concept of MES, Chapter 41 in DAAAM International Scientific Book 2012, pp. 491-508, B. Katalinic (Ed.), Published by DAAAM International, ISBN 978-3-901509-86-5, ISSN 1726-9687, Vienna, Austria DOI: $10.2507 /$ daaam.scibook.2012.41 


\section{Introduction}

The aim of the research to give an overview oriented at practical utilization of production management. Production enterprise's effective development depends on the production system. From the standpoint of management, the key questions are the following: what is the effectiveness of a created production system? How does it affect the development of an organization, and what should be kept in mind? For example, systems should be created keeping in mind the continuous development of organizations. Unfortunately many production enterprises have not created a system for strategic production development and increasing efficiency.

Today globalization is faster than ever due in connection with the deregulation (liberalization) of the real economy and the financial system, which creates a need to improve production systems in order to stay in competition. Our world has also changed along with the development of technology. Today an average car has much more computing capacity than the Apollo rocket that took man to the moon. Even a greeting card that sings Happy Birthday has more computing power than existed in the world in 1950. (Nordström \& Ridderstråle, 2000). In addition, product lifespan and quantity has changed remarkably in industry sectors. In the production organization of the future, the following will be critical:

\section{$>\quad$ Network and cluster \\ $>\quad$ Flexibility and speed (agility) \\ $>\quad$ Innovation (read: ability to change)}

Global corporate clusters are ones that invest into information, school curricula, infrastructure and research that may impact national industry in various ways (Porter 1990). The percentage of systems in the economy as a whole and in the cell - the organization - will become more and more important.

To understand this, nothing more is necessary than to see the changes in products that have taken place around us - how have vehicles such as the aeroplane, car and train changed? Products consisting of several hundred or thousand components have become systems with an exceedingly complicated specification and countless elements that "feed" off of many different research sectors and industrial sector outputs. Many of the complicated products that surround us in today's world cannot be produced using the methodology of the last century. Due to this fact, the necessity of change in systems has accompanied the adoption of new technologies. Integration between different systems, technologies and networks is the key to production and productivity. Developing a production system is a long-term strategic job for an organization that ensures the effectiveness of development.

At the end of the $20^{\text {th }}$ century, industry was transformed by different factors such as standardization, personal computers and various management systems. We have again reached the threshold of successive change, based on integrated e-systems. The advantages of going along with the next industrial revolution wave come precisely from a developed production system. 


\subsection{Research object}

In contemporary industrial society, new platforms and concepts are being developed for future manufacturing systems. In large part, these have been made possible by technological progress and new opportunities based on technology. The primary development engines for controlling manufacturing systems are the ultrarapid development of the Internet and the development of IT and software solutions. The rapid growth of Internet users in historical comparison to the increase in the number of radio listeners, TV audiences or computer users has been many times faster. At the same time, this has imposed new conditions on information technology and software solutions. Considering the achievements and progress of the Internet and information technology in the last decade, these two have created completely new possibilities for managing the supply chain (SC). At the same time, these conditions have set new conditions on managing manufacturing systems in the present day. In the last decade, cheaper labour and automation were the key to competitiveness, but on the basis of MANUFUTURE (http://www.manufuture.org/, 23 February 2012), future advantages will be (HVA - High Value Added) manufacturing, which is based on high performance customization, new business models and people. What challenges face adaptation of such conditions in the future with regard to managing manufacturing systems, and how to determine and evaluate whether the systems are efficacious? This question is unanswered in today's world and requires closer study. In this regard, it is important to find the economic effect and to try to determine the criteria for evaluating the effect.

\subsection{Background}

The effect of a system on humankind is greater than can be imagined. Systems surround our society's social sphere and determine our use of information. Systems are taken for granted and it is not considered important to study such a thing. Yet systems logic and knowledge about a system help create rules and standards that determine quality in both production and our demands as consumers. Upon closer inspection, many things turn out to exhibit a systemic nature. Systems theory has helped us understand the production system's nature and internal nature on a theoretical background.

Irrespective of the type of production organization, the customer's needs remain paramount, and these demands are always expressed in terms of product quality, supply and price. Speed and flexibility are important keywords in creation of contemporary production systems. Competitiveness is determined by improvement of systems in a production enterprise. Considering that the most important constituent elements in improvement of a production system are technology, processes and people, we achieve the maximum result by improving these elements jointly.

Today quality management system development has gone from product inspection to management system models and tools and principles that help an organization achieve its goals in the most effective form possible. Use of management systems depends largely on the production method, whether it is craft, batch or mass production. The structure of the production system and its development depends on the method of production, products, customers and many other factors. At 
the same time, the given management systems are the basis for future trends in industry such as virtual companies and global standards.

The topic is currently a very salient one around the world. Product delivery times are near minimum while demand for efficiency and quality of manufacturing keeps on growing. The topic is especially important in conditions of global competition and an age where new economic and business models are developing. Great changes in the direction of knowledge-based manufacturing control are envisioned in the evolution of manufacturing this century, and these are being made possible due to information systems and technologies. Virtual factories and networks, technology and competence centres are the manufacturing companies and clusters of the future. The existing paradigms of the manufacturing system are changing as these new business models arise, and this provides a significant impetus for new knowledge to take shape.

The capability of increasing productivity is just as important from the standpoint of increasing the international competitiveness of European companies. As has become evident from analysis of training needs conducted by various professional associations, developing productivity is one of the most sought-after development fields. At the same time lacks a full picture of the knowledge of manufacturing enterprises in the field of productivity, mainly focusing on what is taking place on the operational management level.

\subsection{Statement and MES model concept reference system}

Self-organization in conjunction with intelligent integration is the basis of growth in efficiency with regard to manufacturing execution.

Manufacturing has been the basic foundation of the economy and the living environment from the Industrial Revolution to the information era. Manufacturing organizations face a major challenge: developing a manufacturing system and creating an environment in which people are able to practice self-management. In this century, serious pressure has been brought to bear on society in the field of intelligence - increase in competition, globalization, sustainability of production and many other aspects such as the economic downturn and downward pressure on manufacturing costs. One possibility is to improve management systems (including the manufacturing control system) in order to reduce costs. Above all, this means organizations with lower management structure and a smaller number of managers (Nasarwanji et al., 2009). In this context, there is a need to simplify managerial decisions and make the manufacturing system function more effective.

The research goal:

$\checkmark \quad$ Develop model concept of integrated instruments and methods on the basis of which it would be possible to create a MES;

$\checkmark \quad$ Developing manufacturing control in an e-manufacturing environment;

$\checkmark \quad$ Possible developments of manufacturing systems in the field of Intelligent Integration;

What is the economic effect of the system? 
From the standpoint of manufacturing control, standardized information technology solutions have not yet been sufficiently integrated on the basis of methods and instruments that are used in manufacturing.

Use of MES systems has been on the increase only in the last ten years and in the direction of reduced operating costs and greater automation of decisions. MES can be divided into three function groups (Kletti 2007): The functionalities for production, quality and personnel allocation.

In this study, the Lean concept instruments and methods (Womack \& Jones, 2003) will be of assistance in developing the production system.

The basis for developing the concept for the current model is testing integrated Lean concept and developing a structure for the concept of the MES model. The creation of the model is due to the rapid and efficient development through the information technology management system.

\section{MES model concept, methods and applications used}

\begin{tabular}{|l|}
\hline MES EXPERT SYSTEM MODEL: \\
\hline 1. SELECTION OF MANUFACTURING CONCEPT \\
\hline 2. DESIGN OF MANUFACTURING SYSTEM \\
\hline 3. DETERMINING MANUFACTURING METHOD \\
\hline 4. ANALYSIS OF PRODUCT FAMILIES \\
\hline 5. PRODUCT AND MODEL ANALYSIS \\
\hline 6. BUILDING THE STRUCTURE \\
\hline 7. DESCRIPTION OF RESOURCES \\
\hline 8. SELECTION OF DIMENSIONS \\
\hline 9. SYSTEM INTEGRATION \\
\hline
\end{tabular}

Fig. 1. MES model concept

The study was conducted in the framework of the first stage of the emanufacturing concept:

1. Creation of the model concept for developing the management system (MES) for the SME manufacturing enterprise's e-platform (Chen et al., 2002).

2. Finding applications, testing functionality in other companies, adjustments and assessments and documenting the model and applications.

MES gives a company an advantage in planning manufacturing and transmission of information on the operational level; in addition the system independently promotes growth in productivity and quality. The independent capacity of the system for growth in productivity results in a more intelligent manufacturing system. The same is argued by Sousa \& Ramos, 1999 (Zhou et al., 2010): "IMS differs from a conventional manufacturing system - even an advanced one - in its inherent capability to adapt to changes without external intervention." 
Even so, intelligence is not determined by the components of the system but rather how they are integrated with each other. In 1989, Professor H. Yoshikawa (University of Tokyo) defined an Intelligent Manufacturing System or IMS as " $a$ system which improves productivity by systematizing the intellectual aspect involved in manufacturing, flexibly integrating the entire range of corporate activities, production, and marketing (...) so as to foster the optimum in the relationship between men and intelligent machine" (Zhou et al., 2010).

A concept for the MES system model (Fig. 1.) was developed from the applications and factors, integrated with Lean concept instruments consisting of various layers.

The MES expert system model concept consists of the following system development sequence and aspects.

\subsection{Selection of manufacturing concept}

For example: LEAN principle for eliminating waste (Womack et al., 1990), SIX SIGMA principle for statistical quality control (Pande et al., 2002), TQM (principle for total quality control). Activities determining principle and levels.

Even though the history of manufacturing extends back to the distant past, we should start our treatment from the early $20^{\text {th }}$ century in light of the most important aspects of evolution of the manufacturing system. Henry Ford changed the principle behind manufacturing systems by creating an assembly line for production of automobiles. Although such methods were also used before that in slaughterhouses, it was nevertheless one of the greatest and most important stages in the mass production era.

The Toyota phenomenon occurred in the 1950s (Shingo et al., 2000). The need to customize mass production gave an impetus to development of manufacturing systems, which we can consider the second important stage in the transformation of manufacturing systems. No longer could only similar products be produced on assembly lines - the Toyota manufacturing system made it possible, unlike Ford, to produce different colours and models using the same manufacturing system.

As technology developed, flexible manufacturing systems began gaining ground worldwide in the 1980s, which allowed different products to be produced on the same equipment by automating movement of material. Information technology solutions began supporting this direction by allowing control based on predictions and coordination of manufacturing plans. In addition to technological solutions also known as "top-down" systems, thanks to Toyota's manufacturing system, bottom-up systems were also developed - i.e. principles, methods and tools that helped develop manufacturing systems. The world knows the latter largely as the concept "lean manufacturing". Flexible manufacturing systems (Mehrabi et al., 2002) integrated with the lean concept are the world's most common manufacturing system today representing the primary third generation principle.

At the beginning of the $21^{\text {st }}$ century, the development of fourth-generation manufacturing systems is possible thanks to technological developments. The basis for the change in the principle governing new-generation manufacturing systems is intelligent manufacturing. The basis of intelligent manufacturing is intelligent 
technology and system. Yet a paradigm shift is not possible through technological progress alone. Such a change can only be based on total implementation of existing knowledge for the good of fourth-generation (intelligent) manufacturing. For a manufacturing system to take shape, knowledge of various tools and methods is necessary, but the efficacy and use of these methods depends on knowledge of different factors. Awareness of the above makes it possible to understand how to design an intelligent manufacturing system whose primary characteristics are selforganizing ability and flexibility (Mehrabi et al., 2000) as well as an ability to perform self-checks, learn independently, self-development and self-maintenance.

The stages of the development of a manufacturing system are shown in Fig. 2.

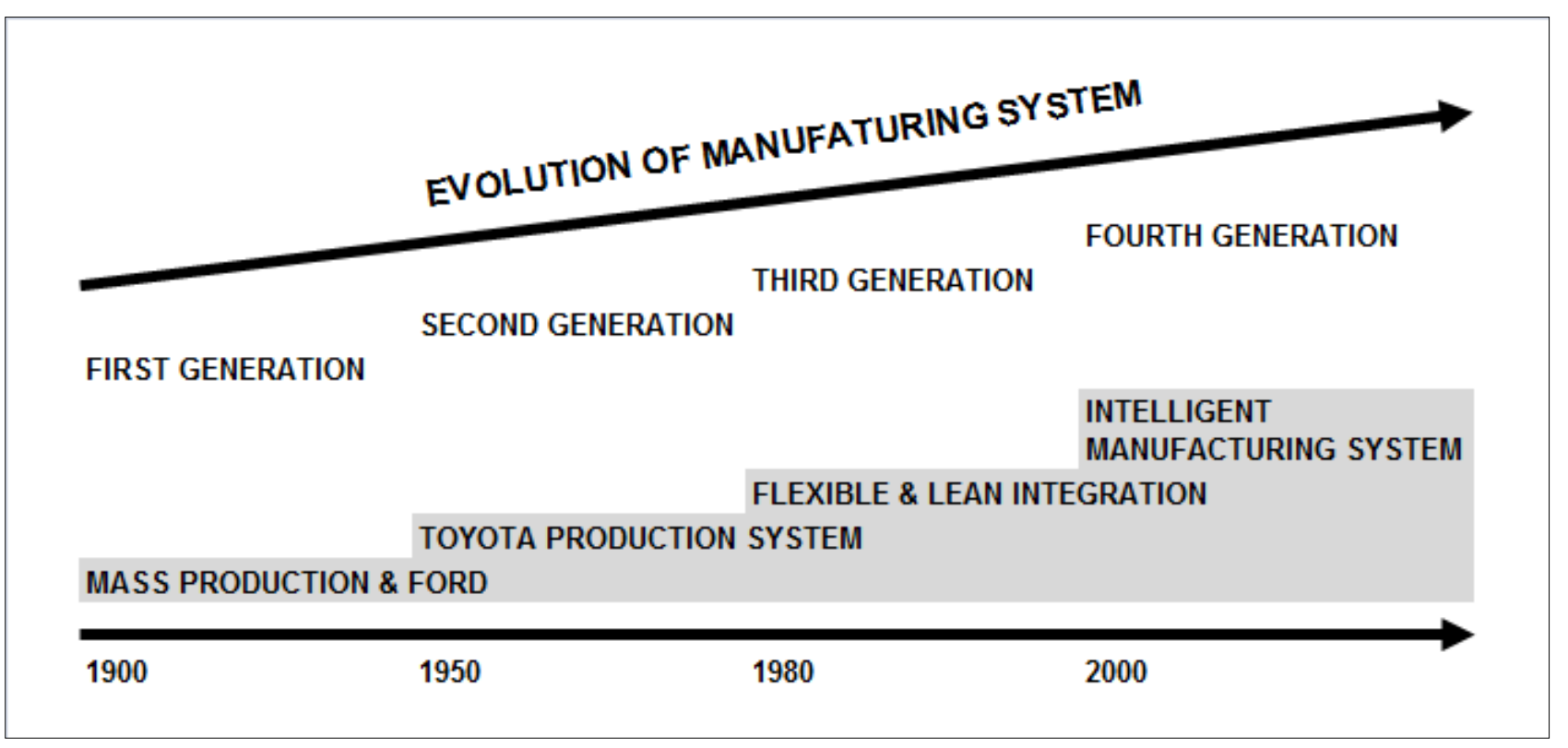

Fig. 2. Stages of the development of manufacturing system

\subsection{Design of a manufacturing system}

Concept methods, for instance: Kanban, Mapping the value stream, Cellular manufacturing. Activity: determining instruments, goals and methods to be used.

An empirical case study was used as a study method, in the course of which observations, data processing and analysis were conducted. On the basis of the results obtained, a management system concept for developing MES was modelled (O'Hare et al., 1990). Based on the case study conducted, the most important factors for efficient development of manufacturing system (principles, instruments and methods) were identified:

$\checkmark \quad$ Methods as Kanban, 5-S (Peterson \& Smith 1998)

$\checkmark \quad$ Demand analysis, Pareto and runners, repeaters, strangers

$\checkmark \quad$ Product families matrix

$\checkmark \quad$ Optimum material flow matrix and schematic

$\checkmark \quad$ Current \& Future value stream map

$\checkmark \quad$ Technology and skills matrix

The basis for measuring the efficiency of the manufacturing system is the Lean concept instrument Total Productive Maintenance (TPM) method Overall Equipment Effectiveness (OEE). The results of key indicators accompanying the OEE method 
show the performance of the said concept. The second key instrument is implementing Kanban in the manufacturing area. In the course of the given study, the launch of the 5-S (work-related organization) project took place in addition to the visual Kanban.

\subsection{Determining manufacturing method}

For example: Project-based approach, manufacturing using standard product, Mass production. Activity: determining manufacturing method.

In 1995 J. Miltenburg came out with the Product process matrix (Miltenburg 1995). The matrix (Table 1) lets us understand the fundamental physics of special manufacturing process, and especially how the products work together as a system. We must pay attention to the nature of variation within it. Intuitive action might even make system performance worse.

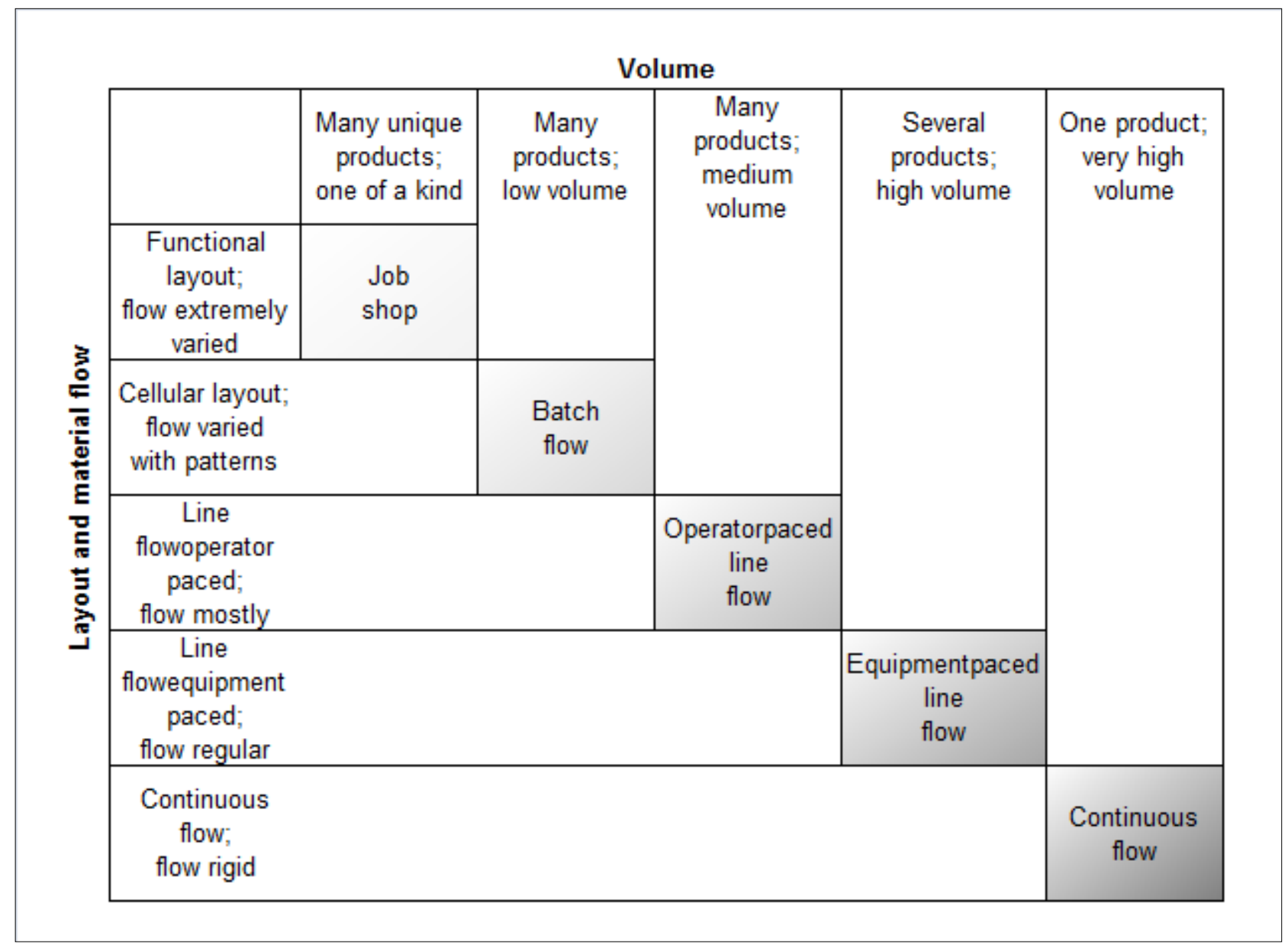

Tab. 1. The Product process matrix (Miltenburg 1995)

The Product process matrix shows the layout and material flow type. Fig. 3. has two different type of layouts accordingly matrix (Table 1). The first shows functional and second Group (flow-line cell) layout (Askin \& Standridge, 1993). As we see,layout design is important part of creating the right production system. 

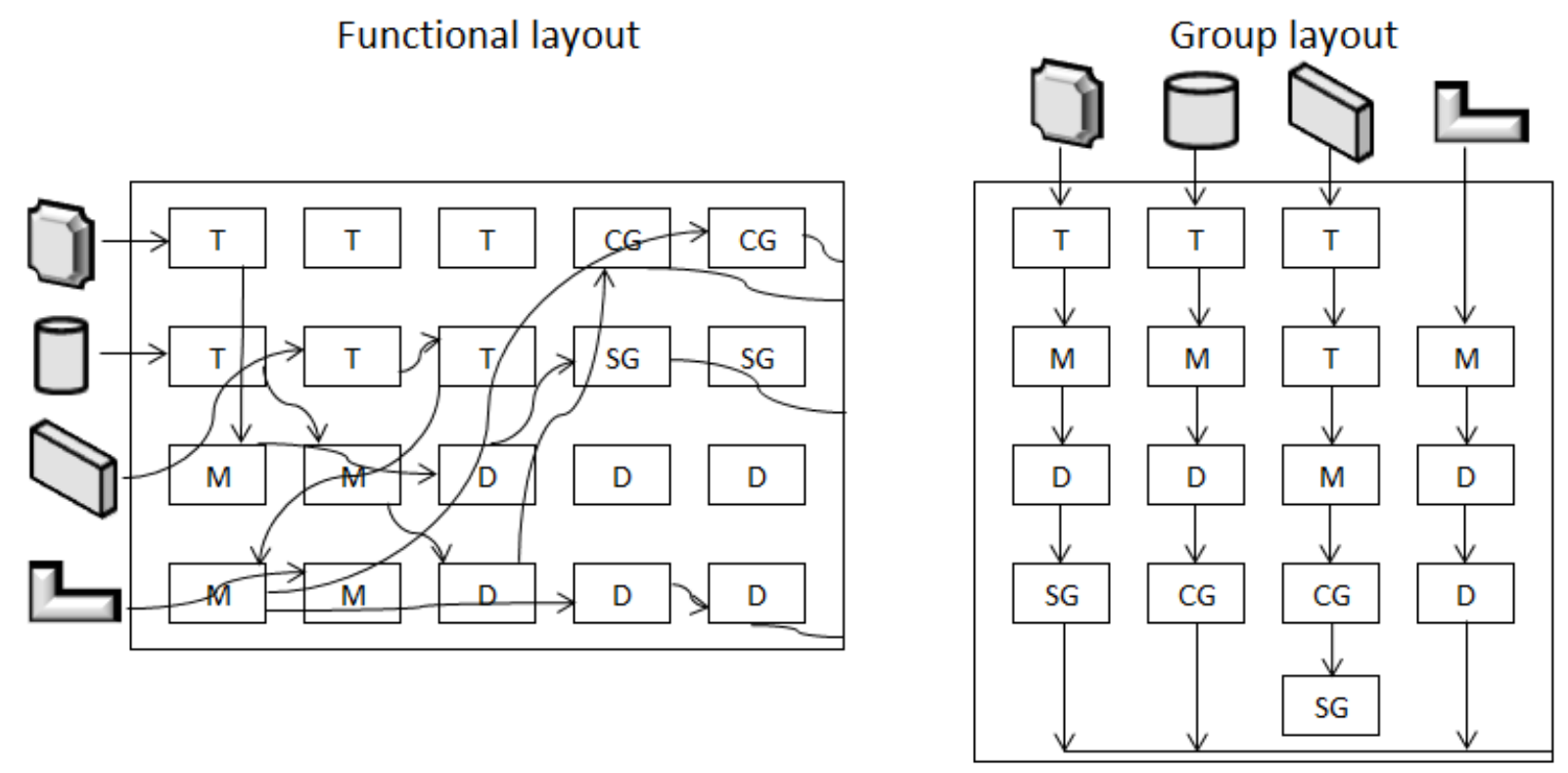

Fig. 3. Functional and Group (flow-line cell) layout (Askin \& Standridge, 1993)

\subsection{Analysis of product families}

Description of products and operations. Activity: clustering. It is important to determine product families as it is not necessary to have a value stream map for each product. It is important to determine which similar processes the products undergo. For this purpose a matrix of the products and of the steps and equipment in the process of producing the product was compiled (Table 2).

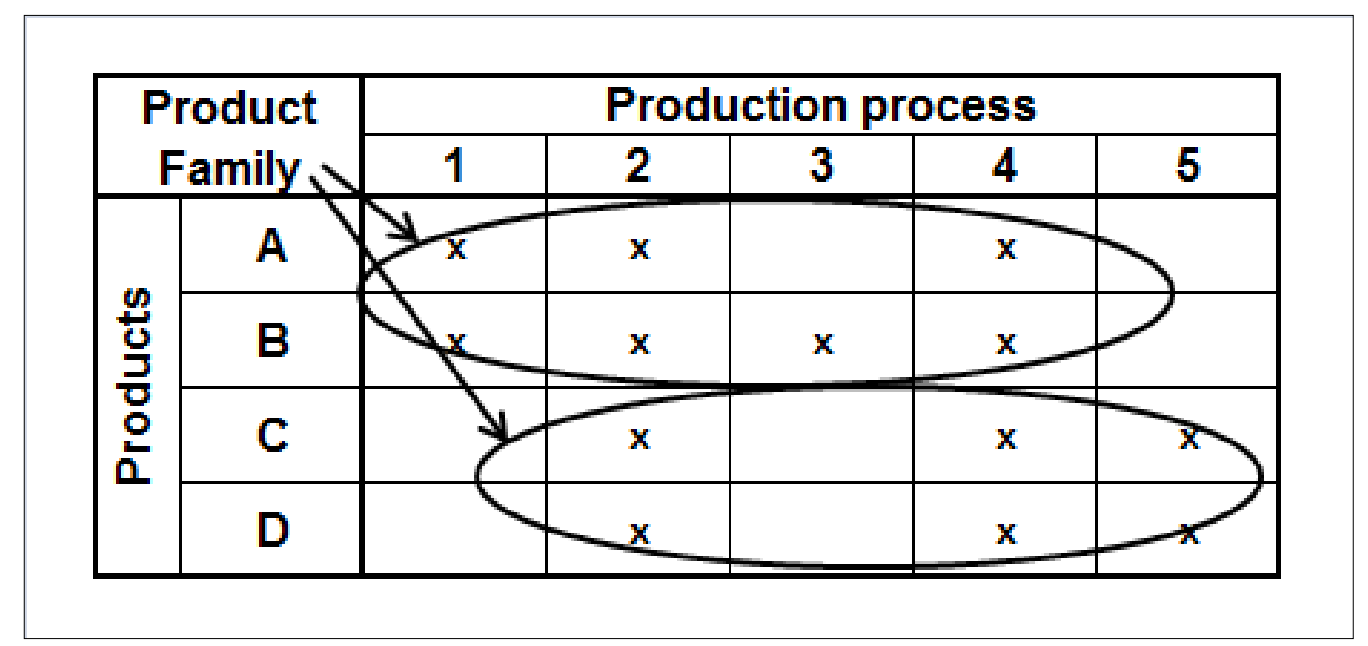

Tab. 2. Matrix of Product Family

\subsection{Product \& model analysis}

Assembling material flow and schematic. Activity: determining when the model becomes product.

Under that layer key value is standardization. Standardizing different subparts in the flow-line we create new models can be used instead several sub-parts. Finally we can create a simplified model for planning and also use more visual Kanban on the 
shop-floor instead of pushing different products through the value stream. Pulling the models can be a final decision a for end product made at the end of the line. It gives change to customize different products and make the production flow more flexible.

\subsection{Building the structure}

Preparing value stream maps (current and future). Activity: pursuant to concept, manufacturing system and method, sequence of families and product/model manufacturing process, description of information and material flow. Principles of group technology and consolidated structure (product families).

Value Stream Mapping (VSM) (Rother \& Shook 2003) is used to find valuegenerating activities through mapping information and material streams. Value stream mapping is supported by many software systems, such as eVMS (http://www.evsm.com, 23. February 2012).

The following steps are used to implement the method:

$\checkmark \quad$ Determine the objects being studied (products, product families) and/or manufacturing functions.

$\checkmark \quad$ Analyze the primary manufacturing indicators (productivity, delivery terms, processing quality, spending on working time, costs on stoppages and other sources of waste) in the given manufacturing situation, select the most significant ones and submit the results of the analysis in the form of a values (waste) map.

$\checkmark \quad$ Evaluate the values of the selected manufacturing indicators

$\checkmark \quad$ Evaluate/forecast the optimum values for manufacturing indicators considering that manufacturing is developed using the principles of lean manufacturing.

$\checkmark \quad$ Develop manufacturing to achieve the planned level of manufacturing indicators.

Mapping the value stream is a method for visualizing the movements of material and information. A value stream map encompasses all stages of the manufacturing process as well as places for storage and loading of raw materials and finished products. From the standpoint of development of the lean manufacturing concept, it is important to map every step in the production process.

The following should be mapped in the manufacturing process:

$\checkmark \quad$ Cycle time

$\checkmark \quad$ Ideal time

$\checkmark \quad$ WIP (Work in Process) - number of products in production at the same time.

$\checkmark \quad$ Movement of material

$\checkmark \quad$ Movement of information

These mapped elements in the manufacturing process give source information for making changes in the future.

The value stream map can be an important document for drawing up a communication plan, business plan or plan of changes. It is expedient to base a company's strategic decisions on the value stream. The first step in the VSM process 
is to prepare the "existing map" and it is good to develop the so-called "future map", the goal of which is to put in place the improvement strategies based on the lean concept.

This approach is the beginning of the process of eliminating waste and helps detect and manage possibilities of reducing waste for the top-level executive, manufacturing employee, planner and supplier.

The goal is to identify and eliminate waste in all business processes.

The benefit of mapping the value stream lies above all in the following:

$\checkmark$ Helps visualize the manufacturing processes on the level of manufacturing unit, not just at the process level;

$\checkmark \quad$ Helps see more than just the waste. VSM allows the sources of waste to be seen throughout the value chain;

$\checkmark \quad$ Shows links in the information and material stream;

$\checkmark \quad$ Shows the potential value stream to be discussed before a decision is made;

$\checkmark \quad$ Is the basis for the improvement plan;

$\checkmark \quad$ Integrates the lean concept and technical possibilities to complement the organization's core values.

It is important to keep in mind that a good value chain map allows an organization to reach the place defined in its goals.

To map the Material and Information Flow, first the process steps and equipment were entered on to the map, along with customer demand, Production Control and, tentatively, supplier(s). Thereafter arrows were added to indicate the direction of the movement of information and materials. After the basic schematic was compiled, the actual measurements took place. The following was determined and marked on the map:

$\checkmark \quad$ Cycle Time (C/T) separately for each step of the process

$\checkmark \quad$ Work in Process or WIP - the quantities of material between steps in the process - converted to Lead Time based on customer demand.

The totals for the data obtained (Production Lead Time and Process Time) were shown separately. This resulted in the Current-State Map seen in Fig. 3.

The sequence of steps in the manufacturing process can clearly be seen in the Value-Stream Mapping process. In manufacturing it is important to understand the principles of Functional Layout - how the functional equipment are situated - and Cellular Layout (Rother \& Shook 2003).

When we look at the existing Current-State Map in Fig. 4, we see how materials move functionally between processes. To some extent the processes are interlinked and cellular groups have been formed. Thus it is only important to make the material flows between cellular groups more fluid. 


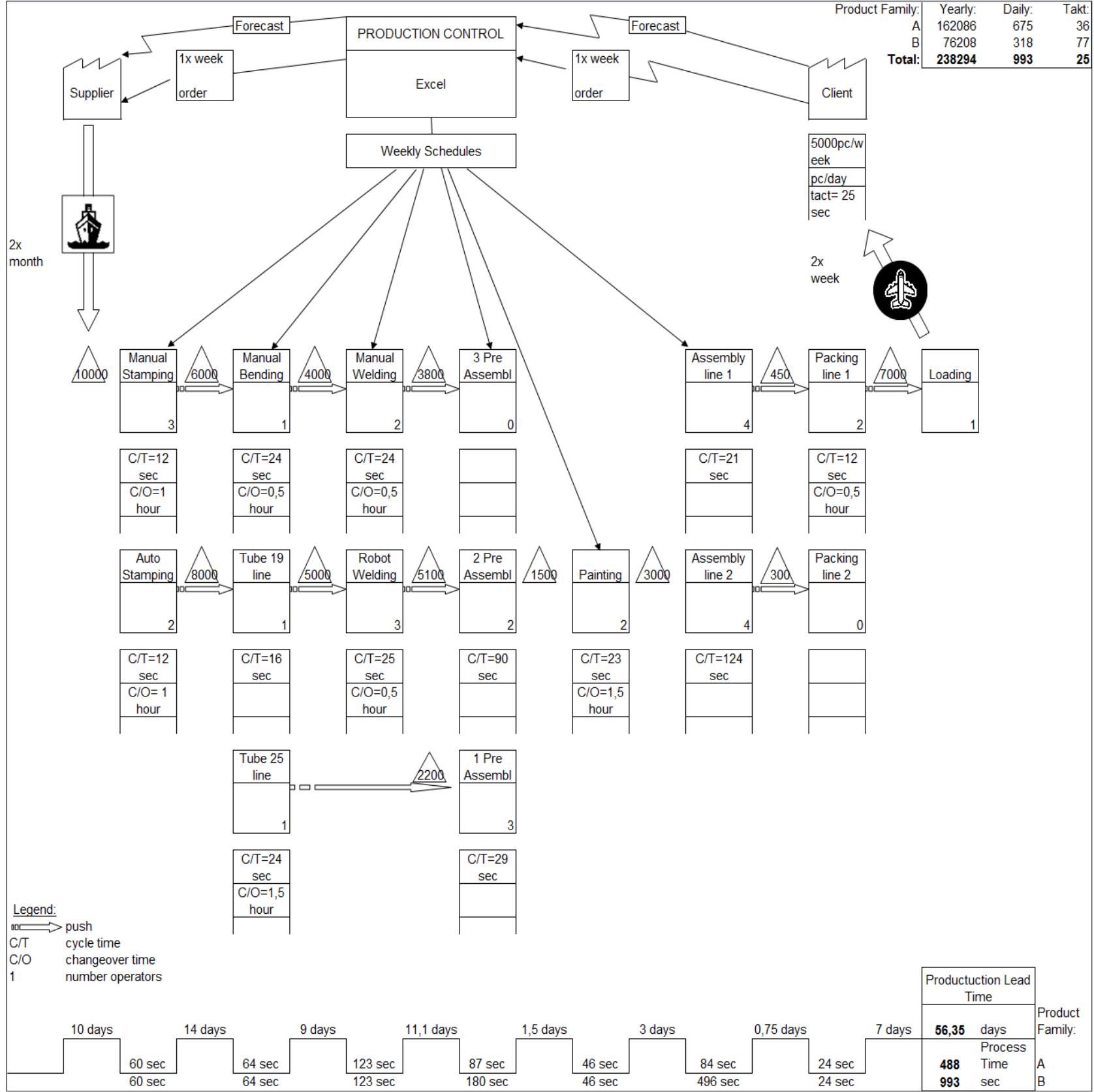

Fig. 4. Current-State Map

Depending on the different durations of Cycle Time (Fig. 3) various methods should be used to synchronize manufacturing. In light of the need to quickly set up manufacturing operations in a new location, it was possible to change the material flow from Push method to the Pull method (Waller 2003). Thus buffers have been calculated to ensure the existence of sufficient material; the buffers are fed accordingly on the basis of the "Kanban" method (Rother \& Shook 2003).

The Future-State Map (Fig. 5.) shows the activities that require improvement and possibilities already in the first stage. 


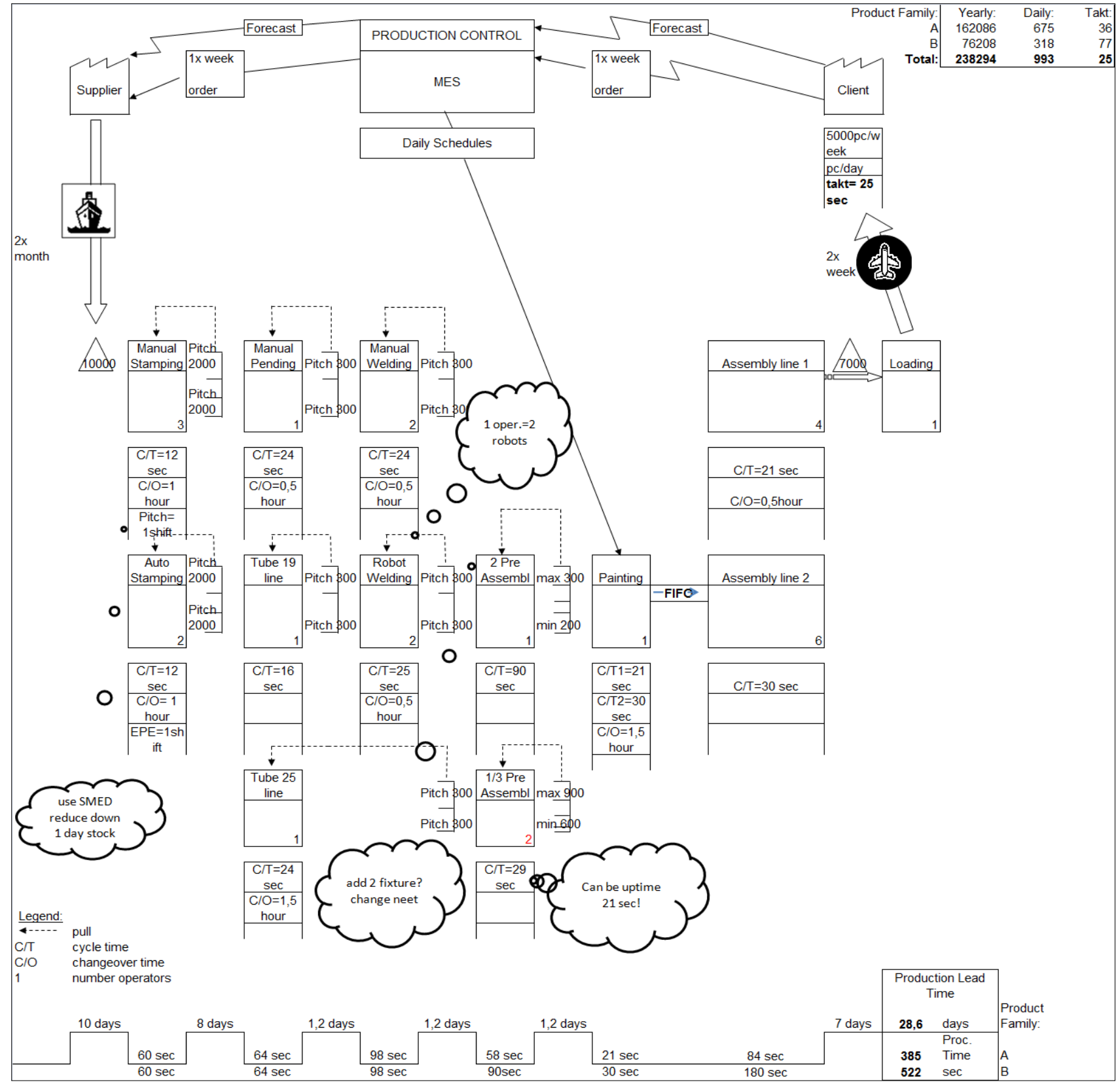

Fig. 5. Future-State Map

\subsection{Description of resources}

Preparing competences and technology matrix. Activity: description of the technology, determining capabilities, determining cycle times.

\begin{tabular}{|c|c|c|c|c|c|c|c|c|c|c|c|c|}
\hline $\begin{array}{l}\text { Competence / } \\
\text { Technology }\end{array}$ & 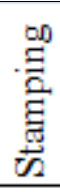 & 吕 & $\stackrel{\text { ڤ }}{\leftrightarrows}$ & 㞭 & 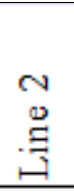 & 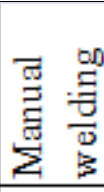 & 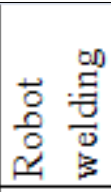 & $\stackrel{\infty}{\Xi}$ & 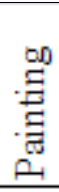 & 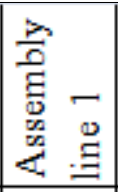 & 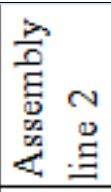 & 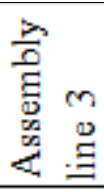 \\
\hline NAME \# & & & $* * *$ & & & & & $* *$ & $* *$ & & ** & \\
\hline NAME \# & & & & & $* * *$ & $* *$ & * & & & & $* *$ & $* *$ \\
\hline NAME \# & * & * & & * & & & & & & * & $* *$ & \\
\hline
\end{tabular}

Tab. 3. Competences and technology matrix 
Above, Table 3 shows a simple method for describing technology recourses and employees' competence. The matrix needed for Advanced Planning System (APS) when human capacity is playing an important role in manufacturing systems. Also when we create a manufacturing execution system, we have to describe both human and technology resources for designing execution logic.

\subsection{Selection of dimensions}

Activity: the temporal dimension of planning is determined, e.g. predictions; "Master plan"; report interval, archival etc. All unnecessary administration work is waste. Therefore creating manufacturing execution system is important to find right dimensions for it. For example time frames for production planning can be shift, day, week, month etc. Controlling system also has to have right time frame. Also product control can be selected according different product type as runners, repeaters, and strangers. Simple way to select these dimensions is Pareto analysis together demand variability (Fig. 6.)

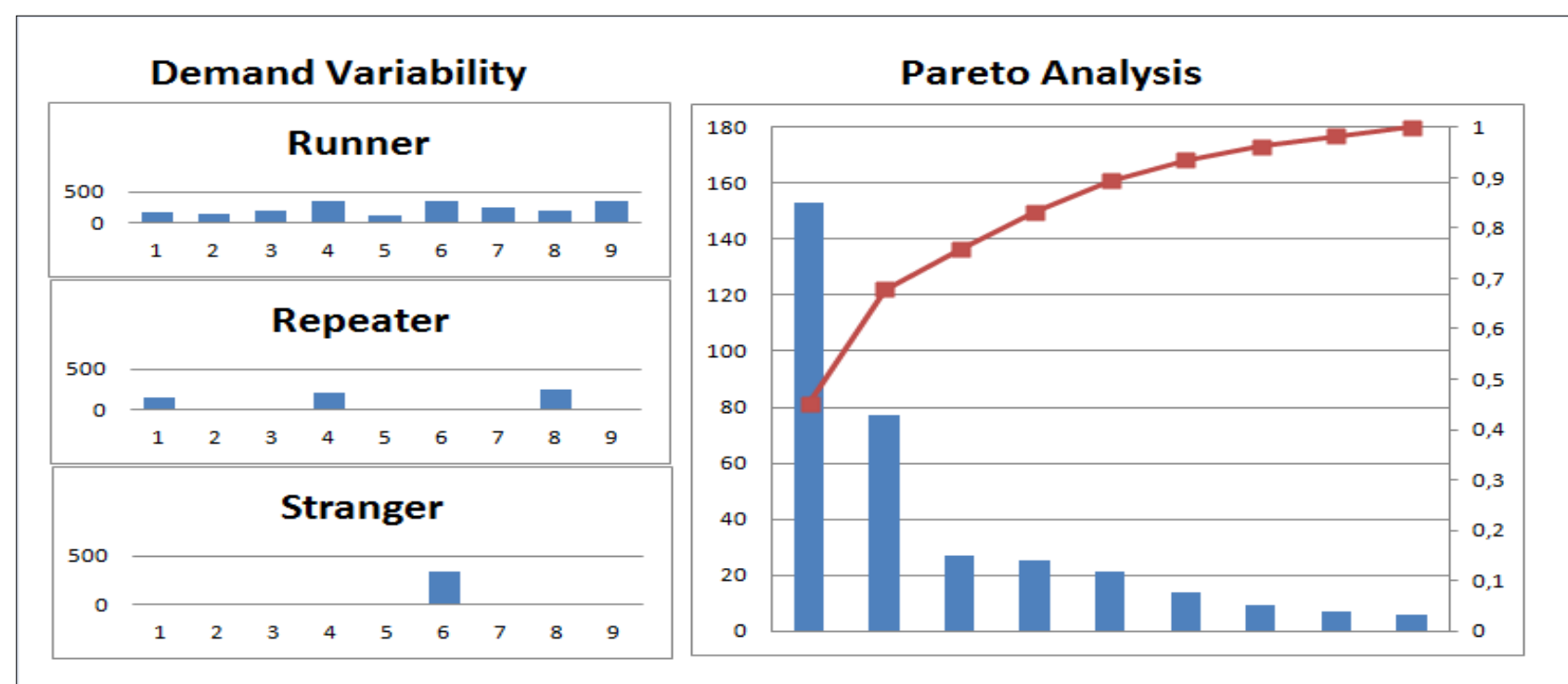

Fig. 6. Demand Variability and Pareto analysis

\subsection{System integration}

Activity: the necessary activities are determined along with integration with other systems, access, etc. Main topics: to find all info technology (IT) systems related to manufacturing and integrate them. All over IT most support to reduce human work. One method to improve the system is to map all processes and activities. Usually we find that many overlapping activities are carried out at a company.

\section{Conclusions}

In this study, studies are carried out in the form of a Case Study consisting of two different important aspects:

$\checkmark$ Developing a concept for a manufacturing execution model from the perspective of a company manufacturing a standardized product 
$\checkmark$ Study of possible applications of IT solutions in the e-manufacturing environment

The need for execution of the solution was based on three aspects:

1. Based on the manufacturing system.

2. The ERP system in use, which lacks flexibility of planning based on manufacturing enterprise needs.

3. Making the manufacturing control system more effective.

The goal of the application was to create an effective planning system. Functionality was achieved in creating the company's planning model and control system.

The application enables:

1. To execute manufacturing planning pursuant to manufacturing typology based on product models. Planning is based on defining product models and their processes.

2. Execute monitoring for tracking OEE (Efficacy, efficiency and quality).

3. Performing work time monitoring.

4. Preparing a competence matrix.

It is possible to add the following to the application:

1. Sharing information in the value chain (distribution of demand in the period).

2. Planning of workforce resource and preparing work schedules.

As a result of the study, a model conception was created (Fig. 1) of integrated instruments and methods on the basis of which it would be possible to create a MES for developing manufacturing control in an e-manufacturing environment. This model has been implemented for developing MES in the e-environment, and the first test results show that manufacturing control has become significantly more efficient, as seen in the growth of productivity and decrease in working time spent on administrative management. During the study period, the growth in effectiveness was $69 \%$. Improvement (I) was calculated using the following formula (1), where the previous state effectiveness is $52 \%$ and new state effectiveness is $88 \%$ :

$$
I=\frac{88 \%-52 \%}{52}=69 \%
$$

In the case of the model concept developed as a result of the study, key factors and instruments are applied in integrated fashion (Shen et al., 2006). The model concept modelled as a result of the study is the key for the structure of the MES system and creation of expert systems. In the course of the case study described, these factors showed clear development in the manufacturing enterprise; this development was based on the selected instruments and integration of these instruments.

In the case of a unified model, it would be possible to carry out a more comprehensive transformation of knowledge (including skills) into the manufacturing enterprise. The author calls the implementation of this method the "golden sphere" idea, i.e. unawares to the company, pursuant to the expert system in manufacturing, rapid productivity growth and/or development as a whole will take place in 
manufacturing. This study does not deal with broader integration of expert systems of enterprises that have a special typology. In the case of this study the model concept should be considered to have been tested in the case of the given manufacturing method. The applications for various manufacturing methods should be tested first.

\section{Limitations and further research}

Based on the author's treatment in the study, the use of the MES model may cause various complications that require further study. With regard to the restrictions below, more detailed analysis has not been performed in the course of this study and they need an additional study. In the author's estimation, significant limitations may arise in the following fields:

$\checkmark$ New Business Models

$\checkmark$ Limitations of new manufacturing system implementation, variable instruments and methods, knowledge management

$\checkmark$ Advanced Planning System (APS) and execution logic

$\checkmark$ Measuring methods for Intelligent Manufacturing

By New Business Models, the author means possible complications that may arise due to reduction of administration. What will communication and company structure be like if the human factor is eliminated, will problems not come up with deficient intelligence of the MES system, what are the interrelations between humanmachine-technology and the resulting synergy?

With regard to limitations related to implementation of the new manufacturing system, this study takes into account exceptions, but an analysis of problems and possibilities related to implementation of various systems is omitted from this study. Nor does the study deal with control of knowledge in this field.

Planning (APS) is one of the most important factors in shaping an MES system. This study creates a model for developing an MES system, but omits the logic for assembling the planning system. This study does not contain a control logic model or algorithms.

There is no uniform solution for measuring Manufacturing System Intelligence according to current scientific paradigms. This study highlights the growth in efficiency stemming from use of the system, but does not define in greater detail growth in intelligence. Based on the limitations of this study, it is important to carry out further and additional studies in the following fields:

$\checkmark$ Knowledge Management through the MES model

$\checkmark$ Virtual Factory and simulation

$\checkmark$ Manufacturing Intelligence measuring methods

Knowledge management in the case of the MES model is especially important in implementation of new manufacturing systems. The primary questions in this field are the following. What are the possible models for the company's development? What technologies and methods support implementation of knowledge upon implementation of MES? Through a virtual factory and simulation it is possible to develop and control, in the case of MES, planning system (APS) and manufacturing system applications. By using a potential new manufacturing system developed on 
the basis of the MES model, we could, through a factory simulation, find deficits and possible solutions for future applications. The most important influence in this field would be on development of model and testing of applications. The author will continue research in this field.

The idea that intelligence could be measured was conceived in the last century when German psychologist and philosopher Louis William Stern laid the groundwork for the concept of Intelligence Quotient (Lamiell 2010). Later Lewis Terman (Kaufman 2009) developed this into the IQ test, based on the work of Alfred Binet (Becker 2003). People's IQ level can be determined by testing. Besides academic intelligence, emotional intelligence (Goleman 2000) and practical intelligence (Sternberg 2003) are distinguished. Today research into intelligence have reached the understanding that humans also have also such a quality as system intelligence (Hämäläinen et al., 2004). Artificial intelligence (Poole et al., 1998; Russell et al., 2003 ) is the intelligence of machines or the simulation of intelligence in machines. In the case of manufacturing systems, this intelligence has been expressed in terms of Business Intelligence (Rud 2009), which defines an organization's abilities and converts them into knowledge though information. Manufacturing Intelligence Quotient has thus far been undefined. Yet it would be quite easy on the macro level to find a common denominator for determining the intelligence of a manufacturing enterprise. The aforementioned indicator should take into account the capability of technology as a system. Based on the above, studying the methods for measuring intelligence of manufacturing systems is a separate topic. From the standpoint of this research, the given field is not of primary importance, but it would be necessary as a basis for evaluating study results and the case study.

\section{References}

Askin R.G. and Standrige C.R. Modelling and Analysis of Manufacturing Systems John Wiley \& Sons Australia, 1993, ISBN 0-471-57369-8

Becker, K.A. 2003. "History of the Stanford-Binet Intelligence scales: Content and psychometrics.".Stanford-Binet Intelligence Scales, Fifth Edition Assessment Service Bulletin No. 1.

Chen, L., Bender, P., Renton, P., El-Wardany, T., Integrated Virtual Manufacturing Systems for Process Optimisation and Monitoring CIRP annals- Manufacturing Technology Volume 51, Issue 1, 2002, Pages 409-412

Goleman, D Emotsionaalne intelligentsus: Miks võib EQ olla tõhusam kui IQ, Väike Vanker 2000

Hämäläinen, R. \&Saarinen, E. Systems Intelligence, Helsinki University of Technology, 2004

Kaufman, A.S. 2009. IQ Testing 101, Springer Publishing Company, ISBN 0-82610629-3ISBN 978-0-8261-0629-2

Kletti, J. 2007. Manufacturing Execution System - MES, Springer Science and Business Media, ISBN 978-3-642-08064-7

Lamiell, J.T.William Stern (1871-1938): A Brief Introduction to His Life and Works. Lengerich/Berlin (Pabst Science Publishers), 2010, ISBN 978-3-89967-589-4 
Mehrabi, M., G., Ulsoy, A., G., Koren, Y., Reconfigurable manufacturing systems: Key to future manufacturing Journal of Intelligent Manufacturing, 11/2000

Mehrabi, M., G., Ulsoy, A., G., Koren, Y., Heytler, P., Trends and perspectives in flexible and reconfigurable manufacturing systems Journal of IM, 13/ 2002

Miltenburg, J. Manufacturing Strategy- How to Formulate and Implement a Winning Plan, Portland, Productivity Press, 1995

Nasarwanji, A.; Pearce, D.; Khoudian, P. \& Worcester, R. (2009). The Impact of Manufacturing Execution Systems on Labor Overheads, Proceedings of the World Congress on Engineering 2009 Vol I, 1-3 July 2009, London, UK, ISBN: 978-988-17012-5-1, IAENG

Nordström, K.A; Ridderstråle, J. (2000). Funky Business: Talent Makes Capital Dance. BookHouse Publishing, ISBN 1-89388-00-3, Stockholm

O'Hare \& Chrisholm, Distributed Artificial Intelligence: An Invaluable Technique for the Development of Intelligent Manufacturing Systems CIRP annalsManufacturing Technology Volume 39, Issue 1, 1990, Pages 485-488

Pande, P.-S., Neuman, R.-P., Cavanagh, R.-R., Киие sigma tee, ISBN 9985-9424-93,Tallinn,Pegasus, 2002

Peterson, J., Smith, R., The 5S Pocket Guide Productivity Press, 1998

Poole, Mackworth \& Goebel, Computational intelligence, Oxford University Press 1998

Porter, M.-E.,The Competitive Advantage of Nations, ISBN0-684-84147-9, NY, 1990

Rother, M. and Shook, J. Learning to See, ISBN 0-9667843-0-8 Brookline, Massachusetts, 2003.

Rud, O. 2009.Business Intelligence Success Factors: Tools for Aligning Your Business in the Global Economy. Hoboken, N.J: Wiley \& Sons. ISBN 978-0470-39240-9.

Russell, Stuart \&Norvig (2003), Artificial Intelligence: A Modern Approach (2nd ed.), Upper Saddle River, New Jersey: Prentice Hall, ISBN 0-13-790395-2

Shen, W., Hao, Q., Yoon, H., J., Norrie, D. H., Applications of agent-based systems in intelligent manufacturingAdvanced Engineering Informatics 20/ 2006

Shingo, S., Andrew P. Dillon, A study of the Toyota production system from an industrial engineering viewpoint. Portland, Oregon: Productivity Press, 1989

Zhou, Z.; Wang, H. \& Lou, P. 2010. Manufacturing Intelligence for Industrial Engineering: Methods for System Self-Organization, Learning, and Adaptation, IGI Global, ISBN 978-1-60566-864-2, United States of America

Waller, D.L. Operations Management: a Supply Chain Perspective 2ndEdition Thompson, London, 2003

Womack, J. \& Jones, D. (2003). Lean Thinking, Simon \& Schuster, ISBN 0-74323164-3, U.K.

Womack, J.-P., Jones, D.-T, Roos, D. The Machine That Changed the World. USA, 1990

***http://www.manufuture.org/, 23. February 2012

***http://www.evsm.com, 23. February 2012 